\title{
Kindergarten Teacher's Knowledge of Enterobiasis in Korea
}

\author{
Dong-Hee Kim¹, Hak-Sun Yu ${ }^{2 *}$ \\ ${ }^{1}$ Department of Nursing, College of Nursing, Pusan National University, Yangsan, South Korea \\ ${ }^{2}$ Department of Parasitology, School of Medicine, Pusan National University, Yangsan, South Korea \\ Email: ${ }^{*}$ hsyu@pusan.ac.kr
}

Received 10 February 2014; revised 25 March 2014; accepted 18 April 2014

Copyright (C) 2014 by authors and Scientific Research Publishing Inc.

This work is licensed under the Creative Commons Attribution International License (CC BY).

http://creativecommons.org/licenses/by/4.0/

(c) (i) Open Access

\begin{abstract}
Previous reports have suggested that the environment of day care centres is a crucial factor in the development of enterobiasis. There is a lack of data regarding a teacher's knowledge about enterobiasis although kindergarten teachers have the greatest influence on a child's habits because the child spends a lot of time with them and because they manage the child's physical environment. The focus of the present study was to evaluate the kindergarten teacher's level of knowledge regarding enterobiasis. The cross-sectional survey is with 287 kindergarten teachers from 36 kindergartens in Korea. The level of knowledge regarding Enterobius vermicularis infection was measured using questionnaires. The percentage of correct answers to questions testing knowledge of enterobiasis ranged from 23.7 percent to 99.3 percent. The average score for the section on knowledge of enterobiasis was 7.85 (possible range: 0 - 12). The question "enterobiasis occurs through contaminated water" had the least correct answer rate $(23.7 \%)$. The findings of this study suggest the need for increasing the kindergarten teacher's knowledge regarding enterobiasis. Educational programs for kindergarten teachers will have a long-term impact on the prevalence of this infection.
\end{abstract}

\section{Keywords}

Enterobius vermicularis; Knowledge; Health Education; Kindergarten

\section{Introduction}

Enterobiasis is caused by infection with Enterobius vermicularis, commonly known as the human pinworm, and is one of the most common childhood parasitic worm infections in worldwide [1]. Forty percent of children were

${ }^{*}$ Corresponding author. 
positive for Enterobius vermicularis eggs in Malaysia [2]. About 20\% of children in Thailand had enterobiasis and the age group 4 - 6 years had the highest positive rate [3]. Remm [4] reported that the prevalence of pinworm infection was 24.4 percent in 954 nursery school children in southeast Estonia. In Korea, enterobiasis has been the most common parasitic infection among children, with prevalence ranging from 7.8 percent to 18.5 percent in both urban and rural areas [5]-[7]. Despite the Korean government's efforts to eradicate the infection during the past decade, the prevalence of this infection has not decreased.

Infection is usually caused by the ingestion or inhalation of pinworm eggs via contaminated fingers (anus-tomouth transfer), contaminated food, and contaminated objects that the children touch [8]. Because children are often exposed to environments that are overcrowded, have inadequate sanitation, and engage in group activities more often than adults, this infection is more common in children [9] [10]. Currently, a number of young children are cared for at kindergartens or nurseries before they enter primary schools. Therefore, the majority of $E$. vermicularis infections in children probably occur in day care centers, because if a single child in a kindergarten is infected with pinworm eggs, then the infection is actively spread to other children and maintained progressively [7] [11].

The main symptom of enterobiasis is itching in and around the anus and around the perineum. Continuous itching causes tearing of skin and complications such as bacterial dermatitis, folliculitis, and acute pain. A significant proportion of children have insomnia, anorexia, weight loss, irritability, and urinary tract infection, along with mental distraction. Generally, the worms enter the vulva and vagina, where they remain for several days, and cause inflammation [12] [13]. Pinworms very rarely penetrate into the submucosa, but when they do, the results are often fatal [9]. Therefore, appropriate treatment and prevention are highly recommended.

Previous reports have suggested that the environment of day care centers, particularly hygienic practices such as hand washing and/or factors such as the cleanliness of the rooms in the kindergarten, is a crucial factor in the development of enterobiasis [2] [7] [14] [15]. School-aged children are old enough to take responsibility of their personal hygiene, but children younger than six years are less responsible than the older ones [16]. Kindergarten teachers have the greatest influence on a child's habits because the child spends a lot of time with them and because they manage the child's physical environment; therefore, evaluating the kindergarten teachers' knowledge regarding enterobiasis is important.

Because of the limited budgets of public health systems, prevention, treatment, and eradication of enterobiasis are difficult. Currently, researchers are aiming to determine whether educational programs that provide fundamental information about pinworm infection can change the rates of this infection by emphasizing the importance of prevention [16] [17]. At present, there is a lack of data regarding a teacher's knowledge about enterobiasis; this data is needed to develop programs for the prevention and control of pinworm infection, and thus to decrease its prevalence. The focus of the present study was to evaluate the kindergarten teacher's level of knowledge regarding enterobiasis.

\section{Methods}

\subsection{Participants}

Among the 176 kindergartens registered with the Ulsan Association of Kindergartens in Korea, 36 kindergartens in five districts of Ulsan agreed to participate in this study. Of the 294 teachers from 36 kindergartens who were invited to participate in this study, 288 (97.9 per cent) agreed to participate. One teacher for whom more than 10 per cent of the relevant survey data were not available was excluded from the study. Finally, the data from 287 teachers were collected and analysed.

\subsection{Questionnaire Design}

Because of the lack of a valid and reliable study instrument, a structured questionnaire was developed by our research team. Literature on parasite infection, including research papers and textbooks, was reviewed. Content validity of this questionnaire was evaluated by three kindergarten teachers who did not participate in the survey, one parasitologist, and two health educators. The participants were asked to evaluate the readability, comprehensibility, and overall quality of the questionnaire. The results and comments obtained after the above-mentioned evaluations were considered while developing the final version of the questionnaire. The questionnaire was used to obtain information regarding the participants' demographic and educational characteristics, their 
experience of education about enterobiasis and necessity of education about enterobiasis, and their general knowledge of enterobiasis. Knowledge of enterobiasis was evaluated under six subcategories; these subcategories included questions regarding the lifespan of $E$. vermicularis, diagnosis of enterobiasis, symptoms and signs of enterobiasis, and the transmission, treatment, and prevention of infection. Answers to these questions were scored as correct (1) or incorrect (0), with a total score of $0-12$.

\subsection{Procedure}

The study was performed after getting approval from the Ethical Review Committee of Pusan National University Hospital and informed consent was obtained from each participant before enrollment. The participants were conveniently recruited from kindergartens in Ulsan from September to October, 2012. The reason we obtained data from Ulsan was because the prevalence of enterobiasis among preschool children in Ulsan recently reported. The average infection rate was $7.8 \%$ which was higher than average rate of enterobiasis reported by Korean government [18]. Ulsan includes the city and agricultural land surrounding the city.

For recruitment, a letter containing information about the nature, significance, and objectives of the study; copies of the questionnaire; and a consent form were sent to the directors of the all kindergartens registered with the Ulsan Association of Kindergartens in Korea. Among 176 kindergartens, 36 kindergartens from all five administrative districts in Ulsan agreed to participate in this study. A researcher outlined the study to the directors and teachers of these kindergartens by using the consent form, letter of information, and questionnaire. All participants, regardless of their specialty, were instructed to complete all parts of the questionnaire. The completed questionnaires were sealed and returned by the participants.

\subsection{Data Analysis}

Data were analysed using SPSS for Windows, version 14 (SPSS, Chicago, IL). The participants' demographic and educational characteristics were expressed as percentages; and their general knowledge of enterobiasis was expressed as percentages and mean \pm standard deviation. Knowledge about $E$. vermicularis infection according to the characteristics of the participants was analysed for t-test and analysis of variance.

\section{Results}

The average age of the teachers who participated in this study was 27.4 years. Among the teachers, 98.3 percent were women, 91.6 percent had graduated college (Table 1). More than 90 percent had never received any education regarding enterobiasis. Among the teachers who had previously received education regarding enterobiasis, 58.0 percent had learned about the prevention of this infection, 41.7 percent knew the symptoms and signs of enterobiasis, and 37.5 percent had learned about the life span of E. vermicularis. Most teachers (92.6\%) thought that education regarding enterobiasis was needed, and 83.5 percent were willing to attend any future educational program. Educational needs were highest in the case of prevention of the infection (83.5\%), knowledge of the symptoms and signs of enterobiasis (69.8\%), and the treatment of enterobiasis (40.5\%) (Table 2).

Table 3 presents the overall proportion of teachers who gave accurate responses to questions testing knowledge regarding enterobiasis. The percentage of correct answers ranged from 23.7 percent to 99.3 percent. The average knowledge score was 7.85 (possible range: 0 - 12). The question "E. vermicularis infection also occurs through contaminated water" had the least correct answer rate (23.7\%); other questions that had low correct answer rates were "Stool examination is the best way to diagnose E. vermicularis infection" (25.1\%), "Group therapy is the most effective therapy for curing E. vermicularis infection" (42.5\%), "Enterobiasis is usually caused by the ingestion of E. vermicularis eggs via contaminated hands" (49.8\%) and "Aggressive behaviour in children can be caused by E. vermicularis infection" (53.3\%). Among the characteristics of participants, age (F $=2.90, p=0.04)$ and recent education of enterobiasis $(F=3.26, p=0.04)$ were associated with the average knowledge score (Table 4).

\section{Discussion}

Although enterobiasis is one of the most common nematode infections among preschool children, there is no national program for prevention and control of this infection in Korea. Most teachers in this study had received college or university education, but only 8.7 percent of them had previously learned about enterobiasis. More- 
Table 1. General characteristics of the participants (N = 287).

\begin{tabular}{ll}
\hline Variable & $\mathrm{n}(\%)$ \\
\hline Gender & \\
Male & $5(1.7)$ \\
Female & $282(98.3)$ \\
Subtotal & 287 \\
Age (years) & \\
$\leq 25$ & $143(50.4)$ \\
$26-30$ & $85(29.9)$ \\
$31-35$ & $26(9.2)$ \\
$\geq 36$ & $30(10.6)$ \\
Subtotal & 284 \\
Education & \\
College & $263(91.6)$ \\
University & $24(8.4)$ \\
Subtotal & 287 \\
\hline
\end{tabular}

Table 2. Past experiences and needs for enterobiasis education $(\mathrm{N}=287)$.

\begin{tabular}{|c|c|}
\hline Variable & n (\%) \\
\hline $\begin{array}{l}\text { Recent education of enterobiasis } \\
\leq 12 \text { month } \\
>12 \text { months } \\
\text { Never } \\
\text { Subtotal }\end{array}$ & $\begin{array}{l}9(3.1) \\
16(5.6) \\
262(91.3) \\
287\end{array}$ \\
\hline $\begin{array}{l}\text { Contents of education }{ }^{* \dagger} \\
\text { Life span of E. vermicularis } \\
\text { Symptoms \& signs } \\
\text { Prevention of infection } \\
\text { Treatment } \\
\text { Subtotal }\end{array}$ & $\begin{array}{l}9(37.5) \\
10(41.7) \\
14(58.3) \\
5(20.8) \\
38\end{array}$ \\
\hline $\begin{array}{l}\text { Necessity of education } \\
\text { Yes } \\
\text { No } \\
\text { Subtotal }\end{array}$ & $\begin{array}{l}263(92.6) \\
21(7.4) \\
284\end{array}$ \\
\hline $\begin{array}{l}\text { Willing to attend future education } \\
\text { Yes } \\
\text { No } \\
\text { Subtotal }\end{array}$ & $\begin{array}{l}238(83.5) \\
47(18.5) \\
285\end{array}$ \\
\hline $\begin{array}{l}\text { Contents of future education } \\
\text { Life span of E. vermicularis }^{\dagger} \\
\text { Symptoms \& signs } \\
\text { Prevention of infection } \\
\text { Treatment } \\
\text { Subtotal }\end{array}$ & $\begin{array}{l}50(20.7) \\
169(69.8) \\
202(83.5) \\
98(40.5) \\
519\end{array}$ \\
\hline
\end{tabular}

over, most teachers thought that education regarding enterobiasis was necessary, and many of them were willing to attend educational programs regarding this infection. The participants thought that education regarding the prevention of enterobiasis and its symptoms and signs was highly necessary. Therefore, health professionals must work with governments to develop strategies, including effective educational programs that address the teachers' needs, and relevant educational methods.

An increase in knowledge does not always lead to a change in the behaviour, but there is a positive association between knowledge and changing behaviour [19]. Vundule and Mharakurwa [20] have reported that knowledge regarding malaria played a significant role in the adoption of preventive measures against that disease. Our findings show that the average score for the section on knowledge of enterobiasis (7.85) was just above the midpoint of the range. Moreover, in our study, the correct answer rates for questions regarding the di- 
Table 3. Knowledge of the participants regarding $E$. vermicularis infection $(\mathrm{N}=287)$.

\begin{tabular}{llc}
\hline Characteristics & $\begin{array}{c}\text { Correct } \\
\text { answer rate (\%) }\end{array}$ \\
\hline 1 & Enterobius vermicularis infection occurs more often in children than in adults. & 71.8 \\
2 & Stool examination is the best way to diagnose $E$. vermicularis infection. & 25.1 \\
3 & The adult worm of $E$. vermicularis migrates to the region around the anus to mate. & 67.9 \\
4 & Some individuals of $E$. vermicularis can migrate to the female genital tract, thereby causing aberrant infection. & 84.0 \\
5 & Aggressive behaviour in children can be caused by E. vermicularis infection. & 53.3 \\
6 & Anal itching (pruritus ani) is one of the most common symptoms of enterobiasis. & 96.9 \\
7 & Enterobiasis is usually caused by the ingestion of $E$. vermicularis eggs via contaminated hands. & 49.8 \\
8 & E. vermicularis infection also occurs through contaminated water. & 23.7 \\
9 & Group therapy is the most effective therapy for curing . vermicularis infection. & 42.5 \\
10 & E. vermicularis infection needs repeat treatment with anthelmintic medication after 2 weeks. & 76.0 \\
11 & E. vermicularis infection is prevented by keeping clean and by drying the bedding in sunlight. & 94.8 \\
12 & It is crucial to practice careful hand washing and to keep the nails short for preventing E. vermicularis infection. & 99.3 \\
\hline
\end{tabular}

Table 4. Knowledge about E. vermicularis infection according to the characteristics of the participants $(\mathrm{N}=287)$.

\begin{tabular}{lcc}
\hline \multicolumn{1}{c}{ Variable } & $\mathrm{M} \pm \mathrm{SD}$ & $\mathrm{t}$ or $\mathrm{F}(p)$ \\
\hline $\begin{array}{l}\text { Gender } \\
\text { Male }\end{array}$ & $7.60 \pm 1.34$ & $0.38(0.71)$ \\
Female & $7.86 \pm 1.53$ & \\
Age (years) & & \\
$\leq 25$ & $7.97 \pm 1.52$ & \\
26 - 30 & $7.96 \pm 1.58$ & $2.90(0.04)$ \\
31 - 35 & $7.62 \pm 1.55$ & \\
$\geq 36$ & $7.13 \pm 1.20$ & \\
Education & & \\
College & $8.00 \pm 1.41$ & $0.27(0.79)$ \\
University & $7.80 \pm 1.51$ & \\
Recent education of enterobiasis & & \\
$\leq 12$ month & $9.11 \pm 1.05$ & $3.26(0.04)$ \\
$>12$ months & $7.88 \pm 1.15$ & \\
Never & $7.80 \pm 1.54$ & \\
Necessity of education & & \\
Yes & $7.87 \pm 1.53$ & $0.44(0.66)$ \\
No & $7.71 \pm 1.49$ & \\
Willing to attend future education & & \\
Yes & $7.86 \pm 1.52$ & $-0.06(0.95)$ \\
No & $7.87 \pm 1.57$ & \\
\hline
\end{tabular}

agnosis of E. vermicularis infection, route of transmission of E. vermicularis, and treatment of this infection were comparatively lower than those for questions regarding hygienic practices followed by the teachers. In particular, among the knowledge questions, less than 50\% of teachers knew contaminated hands spread the infection and just more than 50\% reported correct answer to the question "Aggressive behaviour in children can be caused by E. vermicularis infection". We believed that these two topics are the most important knowledge the teachers should know to prevent and detect of the entrobiasis in a kindergarten. Therefore, health educators should organize health programs that emphasize the diagnosis, transmission, and treatment of enterobiasis in 
kindergartens; the trained teachers can then perform preventive actions such as periodic health screening and prevention of environmental contamination [19].

Anthelmintic therapy on a group basis is one of the most effective tools for the eradication of enterobiasis; however, half the teachers were unaware of this fact. Moreover, only five of the 287 teachers had learned about the treatment of enterobiasis. This unawareness is the reason for the lack of decrease in the prevalence of enterobiasis over the past decade, even though enterobiasis can be readily cured by anthelmintic medications [5] [7] [21]. Kim et al. [18] reported that a kindergarten in which all children, both infected and uninfected, and teachers take anthelmintics at the same time every six months has no cases of enterobiasis; however, other kindergartens with similar environments have higher-than-average rates of E. vermicularis infection. Additionally, the medication proved ineffective in eradicating enterobiasis when children took an anthelmintic medicine only once a year. This is because if each child takes an anthelmintic medicine on a different day of the year, then the child can be reinfected with E. vermicularis within one month after beginning the medication [18].

The group drug therapy issue points to a major failing by public health profession. Teachers may not be responsible for offering medical advice. However, all drug usage may have side effects and treating all children in kindergartens would bring a big financial burden. A previous study conducted by Nithikathkul et al. [16] showed a decrease in infections among school children who received supplementary education. Since teachers are responsible for caring and educating children at a kindergarten, they need to know health information regarding preschool children, to educate the children, and to offer parents about the health information. This is one of safe and effective strategies to reduce the prevalence of enterobiasis among children.

The present study was a preliminary study focused on kindergarten teachers' knowledge of enterobiasis. Further studies should evaluate differences in the pre-intervention and post-intervention knowledge and prevalence of the infection. Selection bias might have influenced our findings. Indeed, it is possible that the teachers who responded to the questionnaire might have had an increased interest in enterobiasis than those who did not to respond. On the other hand, our findings provide useful information regarding the kindergarten teacher's awareness of enterobiasis. This information can be used to develop educational programs for the prevention and control of enterobiasis.

\section{Conclusion}

Our findings suggest that there is a need for increasing the Korean kindergarten teacher's knowledge regarding enterobiasis. Educational programs directed at kindergarten teachers may aid this effort. Health educators can provide adequate information on the prevention, treatment, and eradication of enterobiasis; such efforts will have a long-term impact on the prevalence of this infection among children.

\section{Acknowledgements}

This research was supported by Basic Science Research Program through the National Research Foundation of Koreafunded by the Ministry of Education, Science and Technology (NRF-2013R1A1A1A05012615).

\section{References}

[1] Cook, G.C. and Zumla, A.I. (2009) Manson’s Tropical Diseases. 22nd Edition, Saunders Elsevier, Philadelphia.

[2] Norhayati, M., Hayati, M.I., Oothuman, P., Azizi, O., Fatmah, M.S., Ismail, G. and Minudin, Y.M. (1994) Enterobius vermicularis Infection among Children Aged 1-8 Years in a Rural Area in Malaysia. The Southeast Asian Journal of Tropical Medicine and Public Health, 25, 494-497.

[3] Bunchu, N., Vitta, A., Thongwat, D., Lamlertthon, S., Pimolsri, U., Waree, P., Wongwigkarn, J., Khamsri, B., Cheewapat, R., Wichai, S., Meepayung, T., Thongthung, A., Soypetcasem, S., Buapan, C., Chidburee, P. and Polseela, R. (2011) Enterobius vermicularis Infection among Children in Lower Northern Thailand. Journal of Tropical Medicine \& Parasitology, 34, 36-40.

[4] Remm, M. (2006) Distribution of Enterobiasis among Nursery School Children in SE Estonia and of Other Helminthiases in Estonia. Parasite Research, 99, 729-736. http://dx.doi.org/10.1007/s00436-006-0220-1

[5] Kang, S., Jeon, H.K., Eom, K.S. and Park, J.K. (2006) Egg Positive Rate of Enterobius vermicularis among Preschool Children in Cheongju, Chungcheongbuk-do, Korea. Korean Journal of Parasitology, 44, 247-249. http://dx.doi.org/10.3347/kjp.2006.44.3.247

[6] Park, J.H., Han, E.T., Kim, W.H., Shin, E.H., Guk, S.M., Kim, J.L. and Chai, J.Y. (2005) A Survey of Enterobius ver- 
micularis Infection among Children on Western and Southern Coastal Islands of the Republic of Korea. Korean Journal of Parasitology, 43, 129-134. http://dx.doi.org/10.3347/kjp.2005.43.4.129

[7] Song, H.J., Cho, C.H., Kim, J.S., Choi, M.H. and Hong, S.T. (2003) Prevalence and Risk Factors for Enterobiasis among Preschool Children in a Metropolitan City in Korea. Parasitology Research, 91, 46-50. http://dx.doi.org/10.1007/s00436-003-0836-3

[8] Schmidt, G.D. and Roberts, L.S. (2009) Foundations of Parasitology. 8th Edition, McGraw Hill, New York.

[9] Burkhart, C.N. and Burkhart, C.G. (2005) Assessment of Frequency, Transmission, and Genitourinary Complications of Enterobiasis (Pinworms). International Journal of Dermatology, 44, 837-840. http://dx.doi.org/10.1111/j.1365-4632.2004.02332.x

[10] Lohiya, G.S., Tan-Figueroa, L., Crinella, F.M. and Lohiya, S. (2000) Epidemiology and Control of Enterobiasisin a Developmental Center. The Western Journal of Medicine, 172, 305-308. http://dx.doi.org/10.1136/ewjm.172.5.305

[11] Yoon, H.J., Choi, Y.J., Lee, S.U., Park, H.Y., Huh, S. and Yang, Y.S. (2000) Enterobius vermicularisegg Positive Rate of Pre-School Children in Chunchon, Korea. Korean Journal of Parasitology, 38, 279-281. http://dx.doi.org/10.3347/kjp.2000.38.4.279

[12] Chung, D.I., Kong, H.H., Yu, H.S., Kim, J. and Cho, C.R. (1997) Live Female Enterobius vermicularis in the Posterior Fornix of the Vagina of a Korean Woman. Korean Journal of Parasitology, 35, 67-69. http://dx.doi.org/10.3347/kjp.1997.35.1.67

[13] Deshpande, A.D. (1992) Enterobius vermicularis Live Adult Worms in the High Vagina. Postgraduate Medical Journal, 68, 690-691. http://dx.doi.org/10.1136/pgmj.68.802.690-a

[14] Cook, G.C. (1994) Enterobius vermicularis Infection. Gut, 35, 1159-1162. http://dx.doi.org/10.1136/gut.35.9.1159

[15] Remm, M. and Remm, K. (2009) Effectiveness of Repeated Examination to Diagnose Enterobiasis in Nursery School Groups. Korean Journal of Parasitology, 47, 235-241. http://dx.doi.org/10.3347/kjp.2009.47.3.235

[16] Nithikathkul, C., Akarachantachote, N., Wannapinyosheep, S., Pumdonming, W., Brodsky, M. and Sukthana, Y. (2005) Impact of Health Educational Programmes on the Prevalence of Enterobiasis in Schoolchildren in Thailand. Journal of Helminthology, 79, 61-65. http://dx.doi.org/10.1079/JOH2004272

[17] Blake, J. (2003) An Action Plan to Prevent and Combat Threadworm Infection. Nursing Times, 99, 18-19.

[18] Kim, D.H., Son, H.M., Kim, J.Y., Cho, M.K., Park, M.K., Kang, S.Y., Kim, B.Y. and Yu, H.S. (2010) Parents’ Knowledge about Enterobiasis Might Be One of the Most Important Risk Factors for Enterobiasis in Children. Korean Journal of Parasitology, 48, 121-126. http://dx.doi.org/10.3347/kjp.2010.48.2.121

[19] ElSahn, A.A., Hassan, M.H., Ftohy, E.M., Abou-El Ela, N.E. and Eassa, S.M. (2000) Parasitic Infections and Maternal Awareness of Preschool Children in Karmouz District, Alexandria. Journal of the Egyptian Public Health Association, 75, $1-29$.

[20] Vundule, C. and Mharakurwa, S. (1996) Knowledge, Practices, and Perceptions in Rural Communities of Zimbabwe. Bulletin of World Health Organisation, 74, 55-60.

[21] Kim, B.J., Lee, B.Y., Chung, H.K., Lee, Y.S., Lee, K.H., Chung, H.J. and Ock, M.S. (2003) Egg Positive Rate of Enterobius vermicularis of Primary School Children in Geoje Island. Korean Journal of Parasitology, 41, 75-77. http://dx.doi.org/10.3347/kjp.2003.41.1.75 